Article

\title{
Purification and Characterization of a Novel Insecticidal Toxin, $\mu$-sparatoxin-Hv2, from the Venom of the Spider Heteropoda venatoria
}

\author{
Zhen Xiao ${ }^{\dagger}$, Yunxiao Zhang ${ }^{\dagger}$, Jiao Zeng, Songping Liang, Cheng Tang * and Zhonghua Liu * \\ The National and Local Joint Engineering Laboratory of Animal Peptide Drug Development, College of Life \\ Sciences, Hunan Normal University, Changsha 410081, China; Zhen-Xiao@outlook.com (Z.X.); \\ Zhangyx@smail.hunnu.edu.cn (Y.Z.); Jiaozeng_@outlook.com (J.Z.); liangsp@hunnu.edu.cn (S.L.) \\ * Correspondence: chengtang@hunnu.edu.cn (C.T.); liuzh@hunnu.edu.cn (Z.L.); Tel.: +86-731-8887-2556 (C.T. \& Z.L.) \\ + These authors contributed equally to this work.
}

Received: 18 May 2018; Accepted: 6 June 2018; Published: 7 June 2018

check for updates

\begin{abstract}
The venom of the spider Heteropoda venatoria produced lethal effect to cockroaches as reported in our previous study, and could be a resource for naturally-occurring insecticides. The present study characterized a novel cockroach voltage-gated sodium channels ( $\mathrm{Na}_{V} \mathrm{~s}$ ) antagonist, $\mu$-sparatoxin-Hv2 ( $\mu$-SPRTX-Hv2 for short), from this venom. $\mu$-SPRTX-Hv2 is composed of 37 amino acids and contains six conserved cysteines. We synthesized the toxin by using the chemical synthesis method. The toxin was lethal to cockroaches when intraperitoneally injected, with a $\mathrm{LD}_{50}$ value of $2.8 \mathrm{nmol} / \mathrm{g}$ of body weight. Electrophysiological data showed that the toxin potently blocked Navs in cockroach dorsal unpaired median (DUM) neurons, with an $\mathrm{IC}_{50}$ of $833.7 \pm 132.2 \mathrm{nM}$, but it hardly affected the DUM voltage-gated potassium channels $\left(\mathrm{K}_{\mathrm{V}} \mathrm{s}\right)$ and the DUM high-voltage-activated calcium channels (HVA Cavs). The toxin also did not affect $\mathrm{Na}_{V} s, \mathrm{HVA} \mathrm{Ca}_{V} \mathrm{~s}$, and Kvs in rat dorsal root ganglion (DRG) neurons, as well as $\mathrm{Na}_{\mathrm{V}}$ subtypes $\mathrm{Na}_{\mathrm{V}} 1.3-1.5, \mathrm{Na}_{\mathrm{V}} 1.7$, and $\mathrm{Na}_{\mathrm{V}}$ 1.8. No envenomation symptoms were observed when $\mu$-SPRTX-Hv2 was intraperitoneally injected into mouse at the dose of $7.0 \mu \mathrm{g} / \mathrm{g}$. In summary, $\mu$-SPRTX-Hv2 is a novel insecticidal toxin from $H$. venatoria venom. It might exhibit its effect by blocking the insect $\mathrm{Na}_{V} \mathrm{~s}$ and is a candidate for developing bioinsecticide.
\end{abstract}

Keywords: spider peptide toxin; bioinsecticide; voltage-gated sodium channels

Key Contribution: This study has characterized a novel insecticidal toxin, $\mu$-SPRTX-Hv2, from the venom of the spider $H$. venatoria. This toxin potently blocks cockroach DUM NaVs, but it does not affect mammalian $\mathrm{NaVs}$. It is a candidate for developing bioinsecticide.

\section{Introduction}

Spiders are the most abundant and successful terrestrial predators, and their venoms are cocktails of toxins including cysteine-rich peptides, neurotoxic proteins, histolytic enzymes, digestive enzymes, linear cytolytic peptides, acylpolyamines, small acids, and amines [1]. Among them, cysteine-rich peptide toxins are rich components of most spider venoms. So far, there are over 47,000 recorded spider species (World Spider Catalog, version 19.0), with some spider venoms containing >1000 different peptides [2]. Therefore, there is a great diversity for spider peptide toxins. Many of these toxins had been proven to be insecticidal and some of them are promising bioinsecticide candidates. According to ArachnoServer 3.0 Spider Toxin Database (www.arachnosever.org) [3], 235 out of a total of 1561 recorded spider peptide toxins were considered to be insecticidal based on either experiment data or their sequence similarity to known insecticidal toxins (accessed on 7 May 2018). The chemical insecticides mainly act on six types of molecular targets in the insect nervous system, including the voltage-gated sodium channels 
$\left(\mathrm{Na}_{\mathrm{V}} \mathrm{s}\right)$, glutamate receptors, GABA receptors, nicotinic acetylcholine receptors, acetylcholinesterases, and ryanodine receptors $[4,5]$. While the insecticidal spider peptide toxins shared with chemical insecticides of $\mathrm{Na}_{\mathrm{V}} \mathrm{s}$ as their preferred receptors, they had their own molecular targets in the insect nervous system, including the voltage-gated calcium channels $\left(\mathrm{Ca}_{\mathrm{V}} \mathrm{s}\right)$, lipid bilayer, calcium-activated potassium channels, presynaptic nerve terminals, and NMDA receptors.

Until now scientists have purified and identified lots of insecticidal spider peptide toxins acting on different molecular targets. For instance, $\delta$-ctenitoxin-Pn1a from the venom of Brazilian spider Phoneutria nigriventer [6], $\mu$-hexatoxin-Mg1a and $\mu$-hexatoxin-Mg2a, from the venom of Japanese funnel-web spider Macrothele gigas [7] slowed the fast inactivation of insect $\mathrm{Na}_{V} s$ by associating with the DIV S3-4 extracellular loop (site 3 toxins), and $\delta$-amaurobitoxin-PI1a to -PI1d from the venom of the spider Paracoelotes luctuosus [8] inhibited the peak currents of insect $\mathrm{Na}_{V} \mathrm{~S}$ by binding DII S3-4 extracellular loop (site 4 toxins). The pore region of insect $\mathrm{Na}_{\mathrm{V}} \mathrm{S}$ was also a pharmacological binding site for peptide toxins, and the insect-specific insecticidal toxin Sf1a was speculated to be a pore blocker [9]. Most peptide toxins acting on insect $\mathrm{Navs}$ were gating modifiers, whose binding sites in insect $\mathrm{Na}_{\mathrm{V}} \mathrm{s}$ were distinct from chemical insecticides such as DDT, DDT analogues, and pyrethroids [10]. Thus they might be promising bioinsecticide candidates in terms of managing pests carrying chemical insecticide-resistant $\mathrm{Na}_{\mathrm{V}} \mathrm{s}$ mutations, as a previous study showed a spider toxin was active on pyrethroid-resistant strains of peach-potato aphid although the potency was slightly compromised [11]. It is possible to develop insecticides which discriminate pests from beneficial insects by using insect $\mathrm{Na}_{\mathrm{V}} \mathrm{s}$ as molecular targets, as inspired by the observation that spider toxins $\beta$-Diguetoxin-Dc1a and $\mu$-theraphotoxin-Ae1a even showed selectivity between the highly conserved $\mathrm{PaNa}_{V} 1$ and $\mathrm{BgNa}_{\mathrm{V}} 1$ channels from two cockroach species [12,13]. $\omega$-hexatoxin-Hv1a [14], $\omega$-hexatoxin-Hv2a [15], and $\omega$-theraphotoxin-Hs2a [16] were insecticidal spider toxins acting on the insect Cavs. Now the toxin $\omega$-hexatoxin-Hvla was approved as a bioinsecticide by U.S. Environmental Protection Agency (EPA) [17] and was marketed under the trade name of Spear T (www.vestaron.com). Some toxins showed cross activities to the aforementioned bioinsecticides targets, such as the bifunctional toxin $\mu$-NPTX-Nc1a isolated from the venom of the spider Nephila clavata and the bifunctional toxins $\mu / \omega$-TRTX-Mb1a and $\mu / \omega$-TRTX-Mb1b isolated from the venom of the spider Monocentropus balfouri. $\mu$-NPTX-Nc1a blocked the cockroach $\mathrm{K}_{\mathrm{V}} \mathrm{s}$ and $\mathrm{Na}_{\mathrm{V}} \mathrm{s}$ currents, while $\mu / \omega$-TRTX-Mb1a and $\mu / \omega$-TRTX-Mb1b affected Navs and Cavs currents in the cockroach DUM neurons $[18,19]$. It was assumed that the bifunctional property of $\mu$-NPTX-Nc1a enhanced its insecticidal potency. There were also some insecticidal spider toxins for which their molecular targets were currently unknown, such as the toxins $\mathrm{Ct} 1 \mathrm{a}$ and $\mathrm{Ct} 1 \mathrm{~b}$ isolated from the venom of the spider Coremiocnemis tropix [20], and brachyin, one of the most potent insecticidal toxins, from the venom of the spider Brachypelma albopilosum ( $\mathrm{LD}_{50}$ of $1.02 \mathrm{pm} / \mathrm{g}$ and $1.55 \mathrm{pm} / \mathrm{g}$ of body weight, to cockroaches and meal beetles, respectively) [21]. Taken together, researches aiming at characterizing potent and eco-friendly insecticidal toxin from spider venoms are still ongoing and will provide us with more and more bioinsecticide candidates.

Our previous study showed that the venom of the spider $H$. venatoria produced a lethal effect when intraperitoneally injected into cockroaches, and the venom potently inhibited the DUM NaVs currents [22]. Several peptide toxins have been purified and identified from H. venatoria venom as mammalian $\mathrm{Ca}_{\mathrm{V}} \mathrm{s}$ (patent number US5627154, 6-May-1997) and $\mathrm{K}_{\mathrm{V}} \mathrm{S}$ antagonists [23], while the insecticidal components in this venom were not deeply explored. In the present study, we conducted a full screening of the RP-HPLC purified fractions of $H$. venatoria venom against the DUM $\mathrm{Na}_{\mathrm{V}} \mathrm{s}$ and found that a peptide toxin named as $\mu$-SPRTX-Hv2 was the active component. This toxin potently inhibited the DUM Navs and did not affect the currents of DUM Cavs, DUM $K_{V} s$, as well as mammalian $\mathrm{Na}$ V. It was lethal to cockroaches, but not mice, when intraperitoneally injected. We suggested $\mu$-SPRTX-Hv2 to be a candidate for developing novel bioinsecticide. 


\section{Results}

\subsection{Characterization of $\mu-S P R T X-H v 2$ as a Cockroach $\mathrm{Na}_{V} s$ Toxin}

The venom of the spider H. venatoria was purified by RP-HPLC (Figure 1A), the eluted fractions were lyophilized and their activities to $\mathrm{Na}_{\mathrm{V}} \mathrm{s}$ in acutely dissociated cockroach DUM neurons were tested. This screening analysis confirmed that the fraction with a retention time of 39.4 min was active (Figure 1A, asterisk labeled peak). This fraction was purified to homogeneity by analytical RP-HPLC with a much slower acetonitrile gradient (Figure 1B, asterisk labeled peak). MALDI-TOF MS analysis showed that this peak represented a peptide toxin with the molecular weight of 4169.5102 Da $\left(\mathrm{M}+\mathrm{H}^{+}\right.$, Figure 1C). This toxin potently blocked the DUM Navs currents with an $\mathrm{IC}_{50}$ of $717.8 \pm 40.2 \mathrm{nM}$ (Figure 1D,E, $n=5$ ). We determined its partial sequence by Edman degradation, and blasting this sequence in database matched a peptide toxin with the GenBank accession number of AHF45777.1. Its full sequence was shown in Figure 1F. The theoretical molecular weight (4175.63 Da) of the toxin was 7 Da more than that determined by MALDI-TOF MS analysis, indicating that the six cysteines in its sequence formed three disulfide bonds (minus $6 \mathrm{Da}$ ), and the C-terminus residue of the peptide derived from the cDNA sequences is glycine, which might be considered as the signal of C-terminal amidation (minus $1 \mathrm{Da}$ ). This toxin was described as a secretory peptide in the cDNA library database, and we rationally named the toxin ' $\mu$-sparatoxin-Hv2' (' $\mu$-SPRTX-Hv2', for short) following the nomenclature rules suggested by King, G. F. et al. [24]. We speculated that $\mu$-SPRTX-Hv2 was an ICK motif toxin based on its "C-C-CC-C-C" cysteine framework (Figure 1G, upper panel). Blasting $\mu$-SPRTX-Hv2 full sequence in NCBI showed that it was the most similar to the Cavs toxin $\omega$-SPRTX-Hv1a (patent number US5627154, 06-MAY-1997) characterized in H. venatoria venom (Figure 1G, lower panel), but it showed no significant homology to toxins in other spider venoms. Figure $1 \mathrm{G}$ showed the sequence alignment of $\mu$-SPRTX-Hv2 with several known neurotoxins in $H$. venatoria venom by using MEGA7 [25]. We tested the bioactivity of $\mu$-SPRTX-Hv2 to cockroaches and found it produced lethal effect when intraperitoneally injected, the $\mathrm{LD}_{50}$ was determined as $3.6 \mathrm{nmol} / \mathrm{g}$ of body weight.

\section{2. $\mu$-SPRTX-Hv2 Synthesis and Activity Assay}

We chemically synthesized $\mu$-SPRTX-Hv2 and compared its activity with the native toxin. Figure 2A showed the RP-HPLC purification of the crude synthetics, the asterisk labeled peak contained the $\mu$-SPRTX-Hv2 linear peptide. MALDI-TOF MS analysis determined its molecular weight as 4174.4233 Da, which was 1 Da less than the theoretic molecular weight, as the C-terminus of the synthetic peptide was amidated (Figure 2B). This fraction was collected and lyophilized, and refolded as described in the Materials and Methods section. The refolded toxin was subjected to RP-HPLC purification and was eluted at the acetonitrile gradient of approximately $38 \%$ (Figure 2C). MALDI-TOF MS analysis confirmed its purity and its molecular weight was consistent with the native toxin (Figure 2D). Co-elution experiment in RP-HPLC showed that the native and the synthetic toxins were co-eluted as a single peak (Figure 2E), suggesting their structural consistency. We tested the insecticidal effect of the synthetic toxin, and its $\mathrm{LD}_{50}$ to cockroaches was determined as $2.8 \mathrm{nmol} / \mathrm{g}$ of body weight. The representative current traces in Figure 2F showed that the synthetic toxin potently inhibited the cockroach DUM Navs currents. The dose-response curve superimposed with that of the native toxin, with an $\mathrm{IC}_{50}$ of $833.7 \pm 132.2 \mathrm{nM}$ (Figure $2 \mathrm{G}, n=5$ ). As the co-elution analysis, the bioactivity and the electrophysiology data all showed that the synthetic and native $\mu$-SPRTX-Hv2 were almost identical, we used the synthetic toxin for further experiments. The toxin did not affect the currents of DUM HVA $\mathrm{Ca}_{\mathrm{V}} \mathrm{s}$ even at a concentration of $10 \mu \mathrm{M}$ (Figure $2 \mathrm{H}$, left, $n=4$ ). For $\mathrm{K}_{\mathrm{V}}$ s currents, $10 \mu \mathrm{M}$ toxin only caused a weak inhibition by approximately $15.4 \pm 0.1 \%$ (Figure $2 \mathrm{H}$, right, $n=4$ ). 

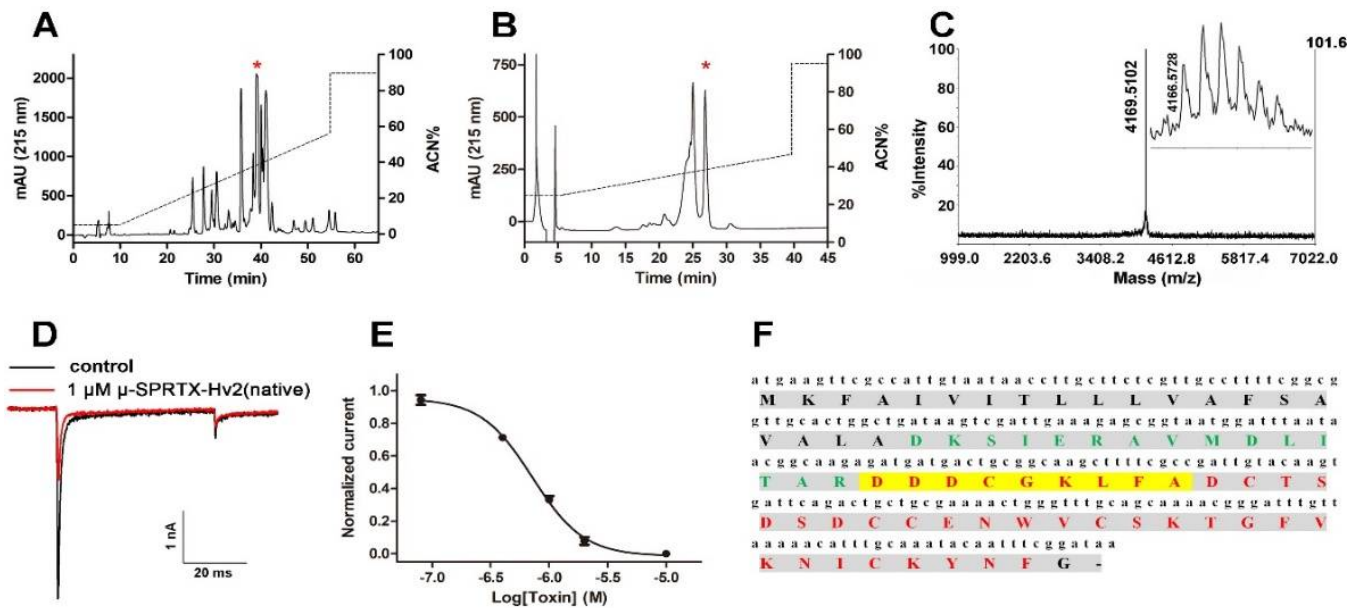

$\mathbf{G}$

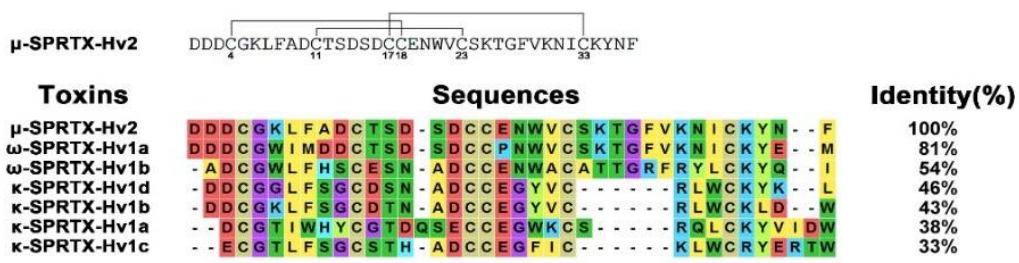

Figure 1. Purification and characterization of $\mu$-SPRTX-Hv2. (A) RP-HPLC profile of H. venatoria venom, the asterisk indicated the peak containing $\mu$-SPRTX-Hv2; (B) $\mu$-SPRTX-Hv2 was purified to homogeneity by analytical RP-HPLC, the asterisk * indicated the $\mu$-SPRTX-Hv2 peak; (C) MALDI-TOF MS analysis of purified $\mu$-SPRTX-Hv2, and inset was an enlarged view of the peak; (D) $\mu$-SPRTX-Hv2 potently blocked the peak currents of cockroach DUM Navs. Currents were elicited by depolarizations to $0 \mathrm{mV}$ from the holding potential of $-90 \mathrm{mV}$; (E) Dose-response curve for $\mu$-SPRTX-Hv2 blocking DUM NaVs $(n=5)$; (F) Full sequence of $\mu$-SPRTX-Hv2. The signal peptide was shown in black bold, the propeptide was shown in green bold, and the mature peptide was shown in red bold. The sequence determined by Edman degradation was highlighted in yellow; (G) Speculated disulfide framework of $\mu$-SPRTX-Hv2 and sequence alignment of $\mu$-SPRTX-Hv2 with toxins characterized in $H$. venatoria venom (the SPRTXs). The residues D and $\mathrm{E}$ were shaded in red; $\mathrm{M}, \mathrm{V}, \mathrm{A}, \mathrm{L}, \mathrm{I}$, and $\mathrm{F}$ were shaded in yellow; $\mathrm{G}$ was shaded in fuchsia; W, T, S, Q, and N were shaded in green; $\mathrm{C}$ was shaded in olive; $\mathrm{Y}$ was shaded in lime; and $\mathrm{H}, \mathrm{K}, \mathrm{R}$, and $\mathrm{P}$ were shaded in teal.

\section{3. $\mu$-SPRTX-Hv2 did not Affect Gating Kinetics of DUM Na $a_{V}$}

Peptide toxins inhibited the $\mathrm{Na}_{\mathrm{V}} \mathrm{s}$ currents either by modifying the activation kinetics or by physically occluding the ion conducting pathway. The toxin $\mu$-SPRTX-Hv2 rapidly inhibited the DUM Na $\mathrm{V}$ currents, and the time constant for toxin associating with the channel was determined as $13.8 \pm 1.7 \mathrm{~s}$ by fitting the decay phase of the trace in Figure 3A. Its effect could not be washed off by bath solution perfusion (Figure 3A), suggesting a very stable binding of the toxin with the channel. To explore the effect of $\mu$-SPRTX-Hv2 on the I-V relationship of DUM Navs, family currents were elicited by serials of 50-ms depolarizations from $-80 \mathrm{mV}$ to $+80 \mathrm{mV}$ (in $10 \mathrm{mV}$ increment) before and after the application of $1 \mu \mathrm{M}$ toxin. Figure 3B showed the representative current traces before and after $1 \mu \mathrm{M} \mu$-SPRTX-Hv2 treatment. The toxin blocked the currents at all voltage tested, but did not affect the initial activation voltage, the peak current voltage and the reversal voltage (Figure $3 C, n=5$ ). The steady-state activation curves before and after $1 \mu \mathrm{M}$ toxin treatment almost superimposed ( $\mathrm{V}_{\mathrm{a}}$ was $-24.7 \pm 2.6 \mathrm{mV}$ and $-23.0 \pm 3.7 \mathrm{mV}, \mathrm{K}_{\mathrm{a}}$ was $3.6 \pm 0.5 \mathrm{mV}$ and $4.4 \pm 0.4 \mathrm{mV}$, before and after $1 \mu \mathrm{M}$ toxin treatment, respectively; Figure $3 \mathrm{D}, n=5$ ). Furthermore, the toxin did not change the steady-state inactivation of DUM Na $\mathrm{V}_{\mathrm{V}}\left(\mathrm{V}_{\mathrm{h}}\right.$ was $-36.0 \pm 4.5 \mathrm{mV}$ and $-38.7 \pm 4.1 \mathrm{mV}, \mathrm{K}_{\mathrm{h}}$ was $-5.3 \pm 0.3 \mathrm{mV}$ and $-5.4 \pm 0.3 \mathrm{mV}$, before and after $1 \mu \mathrm{M}$ toxin treatment, 
respectively; Figure 3E, $n=5$ ). These data suggested that $\mu$-SPRTX-Hv2 inhibited the peak currents of DUM Navs without affecting the gating kinetics.
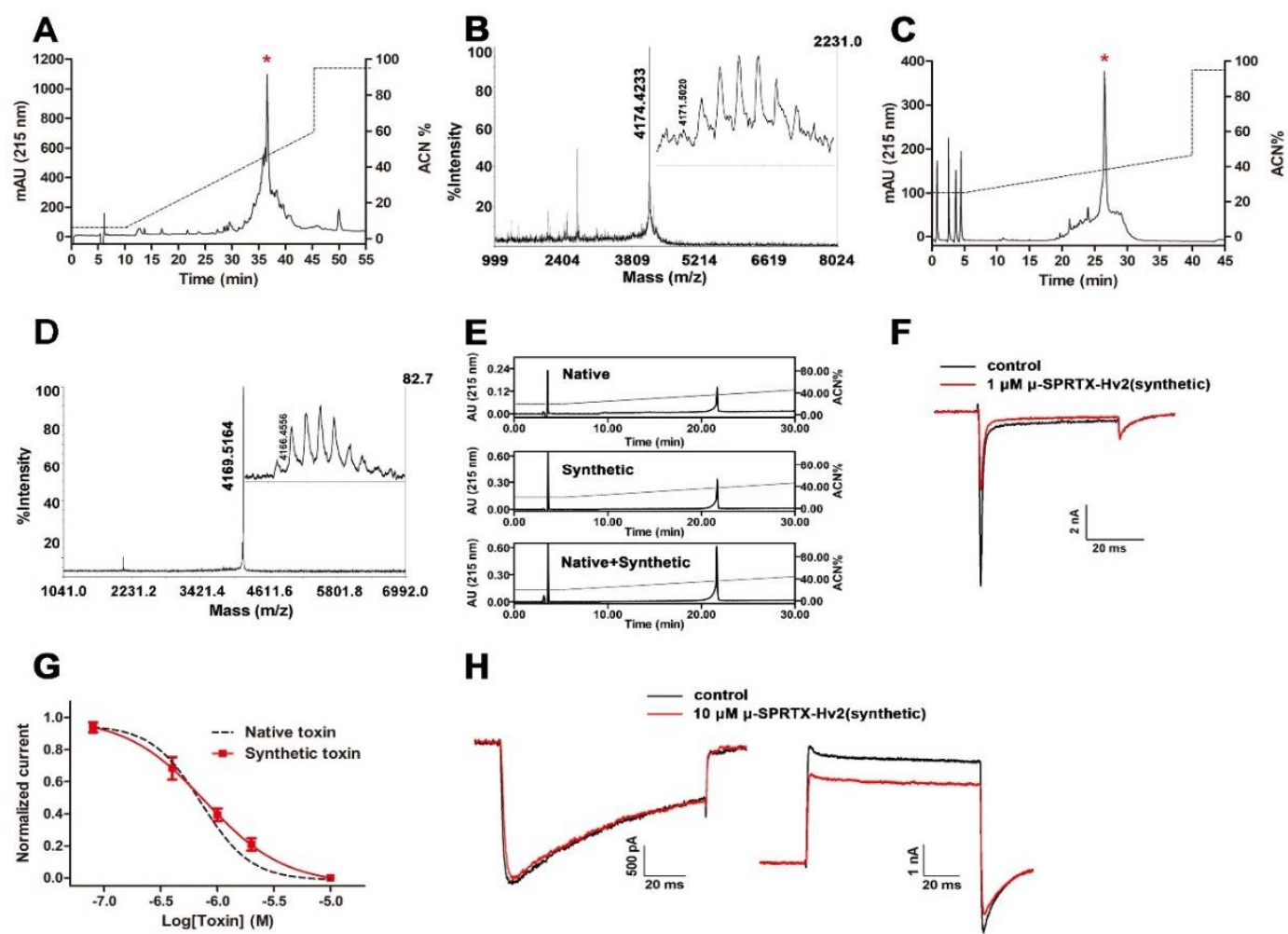

Figure 2. Effects of synthetic $\mu$-SPRTX-Hv2 on cockroach DUM ion channels. (A) RP-HPLC purification of crude synthetics of $\mu$-SPRTX-Hv2, and asterisk indicated the peak containing $\mu$-SPRTX-Hv2 linear peptide; (B) MALDI-TOF MS analysis of $\mu$-SPRTX-Hv2 linear peptide; (C) Analytical RP-HPLC purification of refolded $\mu$-SPRTX-Hv2, and asterisk indicated the correctly-refolded toxin; (D) MALDI-TOF MS analysis of the refolded $\mu$-SPRTX-Hv2, and inset was an enlarged view of the peak; (E) RP-HPLC co-elution experiment of native and synthetic $\mu$-SPRTX-Hv2; (F) Representative traces showed $1 \mu \mathrm{M}$ synthetic $\mu$-SPRTX-Hv2 potently inhibited the DUM Na $\mathrm{V}_{\mathrm{S}}$ currents. Currents were elicited by $50-\mathrm{ms}$ depolarizations to $0 \mathrm{mV}$ from the holding potential of $-90 \mathrm{mV}$; $(\mathbf{G})$ Dose-response curve for synthetic $\mu$-SPRTX-Hv2 blocking DUM $\mathrm{Na}_{V}$ s. The $\mathrm{IC}_{50}$ was determined as $833.7 \pm 132.2 \mathrm{nM}(n=5)$. The curve for native toxin was shown in black dashed line; $(\mathbf{H})$ Left: representative traces showed $10 \mu \mathrm{M}$ synthetic $\mu$-SPRTX-Hv2 did not affect the currents of DUM HVA Ca $\mathrm{V}_{\mathrm{V}}$ s. Currents were elicited by $100-\mathrm{ms}$ depolarizations to $-30 \mathrm{mV}$ from a holding potential of $-80 \mathrm{mV}(n=4)$; Right: $10 \mu \mathrm{M}$ synthetic $\mu$-SPRTX-Hv2 inhibited the DUM $\mathrm{K}_{\mathrm{V}} \mathrm{s}$ currents by approximately $15.4 \pm 0.1 \%$, currents were elicited by 100 -ms depolarizations to $+20 \mathrm{mV}$ from a holding potential of $-80 \mathrm{mV}(n=4)$.

\section{4. $\mu$-SPRTX-Hv2 did not Act on Mammalian $\mathrm{Na}_{V} s$ and $\mathrm{Ca} a_{V}$}

We tested the toxicity of $\mu$-SPRTX-Hv2 to mouse by intraperitoneally injecting toxin at the dose of $7.0 \mu \mathrm{g} / \mathrm{g}$, and no obvious envenomation symptoms were observed $(n=3)$. We also tested the activities of $\mu$-SPRTX-Hv2 on mammalian ion channels. The data showed that $15 \mu \mathrm{M} \mu$-SPRTX-Hv2 did not affect the currents of tetrodotoxin sensitive $\mathrm{Na}_{V} \mathrm{~s}$ (TTX-S Navs) and the HVA Cav in acutely dissociated rat DRG neurons (Figure 4A,B). For heterologously expressed $\mathrm{Na}_{\mathrm{V}}$ subtypes, $15 \mu \mathrm{M}$ toxin weakly inhibited the $\mathrm{Na}_{V} 1.3$ and $\mathrm{Na}_{V} 1.4$ currents by less than $10 \%$, and did not affect $\mathrm{Na}_{V} 1.5, \mathrm{Na}_{V} 1.7$, and $\mathrm{Na}_{\mathrm{V}} 1.8$ currents (Figure $4 \mathrm{C}-\mathrm{G}$ ). 
A

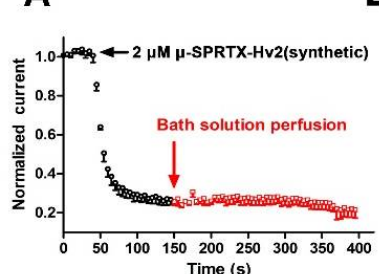

B
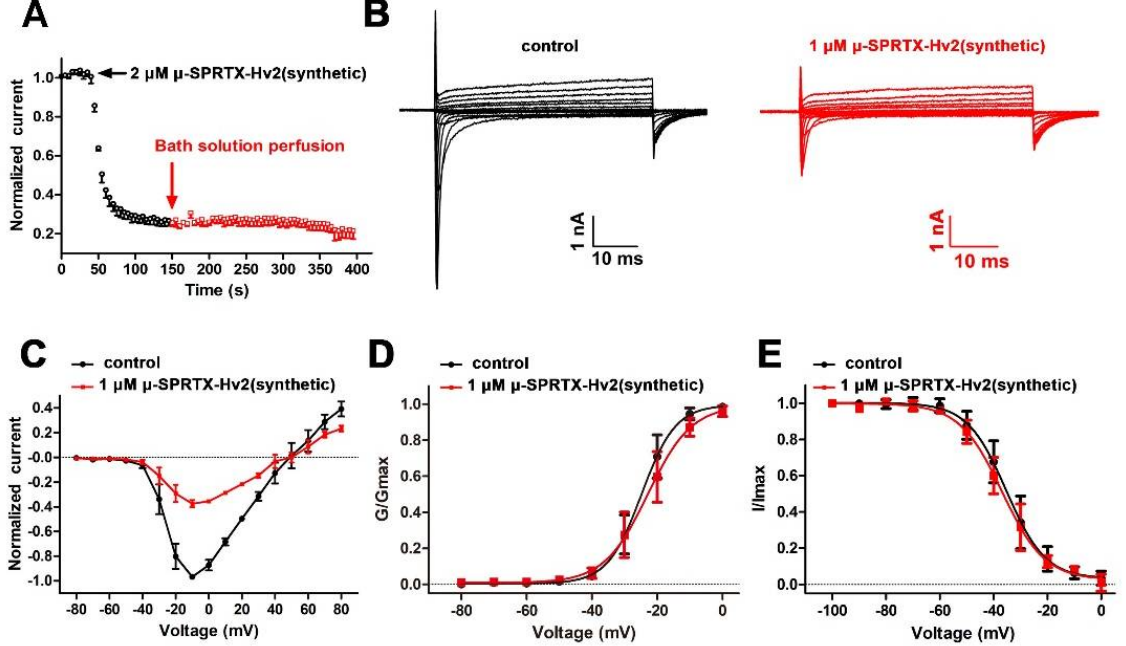

Figure 3. Kinetics of $\mu$-SPRTX-Hv2 interacting with DUM Navs. (A) The time course for $\mu$-SPRTX-Hv2 inhibiting DUM NaVs currents, and the blocking effect is irreversible. Currents were elicited by 80 consecutive sweeps (each sweep contains a 50-ms depolarization to $0 \mathrm{mV}$ from the holding potential of $-90 \mathrm{mV}$, and the sweep interval was set to be $5 \mathrm{~s}$ ), normalized to that in the first sweep and plotted as a function of time. The association time constant $\left(\tau_{\text {on }}\right)$ was determined as $13.8 \pm 1.7 \mathrm{~s}$; (B) Representative DUM Navs currents before and after $1 \mu \mathrm{M} \mu$-SPRTX-Hv2 treatment. Currents were elicited by a cluster of depolarizations from $-80 \mathrm{mV}$ to $+80 \mathrm{mV}$, in $10 \mathrm{mV}$ increment, from the holding potential of $-90 \mathrm{mV}$; (C) I-V relationships of DUM Navs before and after $1 \mu \mathrm{M} \mu$-SPRTX-Hv2 treatment $(n=5)$; (D) The G-V curves of DUM Na $\mathrm{V}_{\mathrm{V}}$ before and after $1 \mu \mathrm{M} \mu$-SPRTX-Hv2 treatment $\left(\mathrm{V}_{\mathrm{a}}\right.$ was $-24.7 \pm 2.6 \mathrm{mV}$ and $-23.0 \pm 3.7 \mathrm{mV}$, slope factor was $3.6 \pm 0.5 \mathrm{mV}$ and $4.4 \pm 0.4 \mathrm{mV}$, for control and toxin treated channels, respectively; $n=5$ ); (E) The steady-state inactivation curves of DUM NaVs before and after $1 \mu \mathrm{M} \mu$-SPRTX-Hv2 treatment $\left(\mathrm{V}_{\mathrm{h}}\right.$ was $-36.0 \pm 4.5 \mathrm{mV}$ and $-38.7 \pm 4.1 \mathrm{mV}$, slope factor was $-5.3 \pm 0.3 \mathrm{mV}$ and $-5.4 \pm 0.3 \mathrm{mV}$, for control and toxin treated channels, respectively; $n=5$ ). A standard two-pulse protocol was used, in which a $500-\mathrm{ms}$ conditional pulse ranged from $-100 \mathrm{mV}$ to $0 \mathrm{mV}$ was followed by a test pulse to $-10 \mathrm{mV}$.

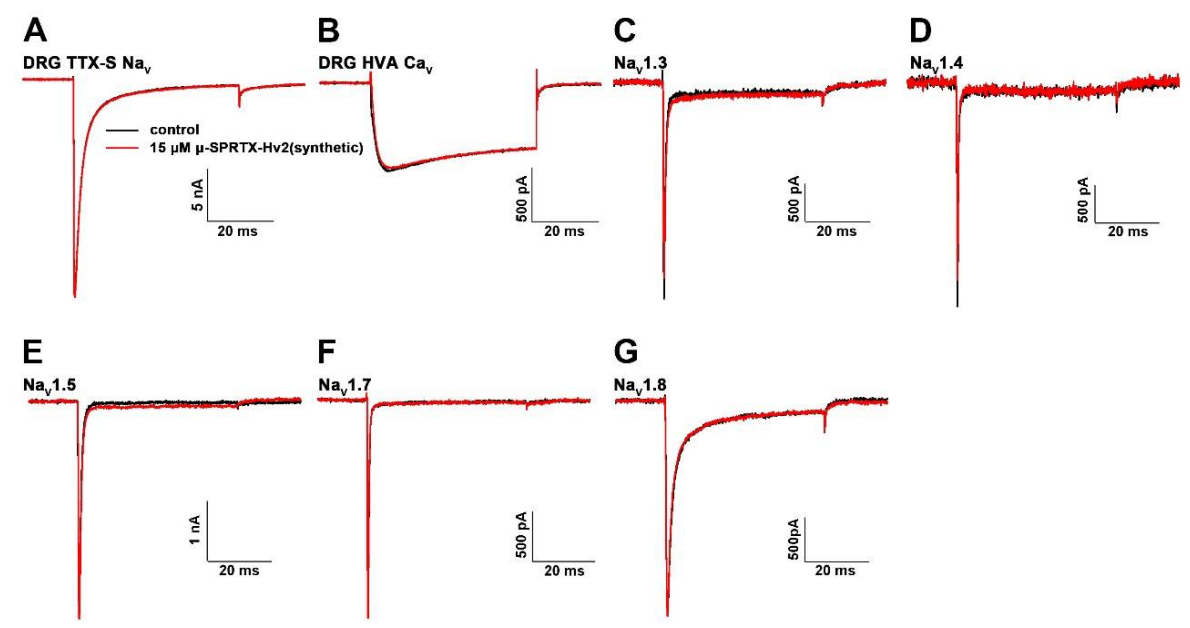

Figure 4. Effects of $\mu$-SPRTX-Hv2 on mammalian ion channels. (A,B) $15 \mu \mathrm{M} \mu$-SPRTX-Hv2 did not affect the currents of TTX-S Navs and HVA CaVs in rat DRG neurons $(n=5$ for each type of currents); (C-G) $\mathrm{Na}_{\mathrm{V}} 1.3, \mathrm{Na}_{\mathrm{V}} 1.4, \mathrm{Na}_{\mathrm{V}} 1.5$, and $\mathrm{Na}_{\mathrm{V}} 1.7$ channels were heterologously expressed in HEK293T cells, $\mathrm{Na}_{V} 1.8$ channel was heterologously expressed in ND7/23 cells. Currents were elicited by depolarizations to $+10 \mathrm{mV}$ from a holding potential of $-80 \mathrm{mV}$. These $\mathrm{Na}_{\mathrm{V}}$ subtypes were resistant to high dose $(15 \mu \mathrm{M})$ toxin treatment ( $n=5$ for each type of channel). 


\section{Discussion}

The present study has purified and characterized an insecticidal toxin, $\mu$-SPRTX-Hv2, from the venom of the spider $H$. venatoria, this toxin possibly functions by blocking the insect $\mathrm{Na}_{\mathrm{V}} \mathrm{s}$. $\mu$-SPRTX-Hv2 did not affect the currents of HVA $\mathrm{Ca}_{V} s$ and $\mathrm{Na}_{V} s$ in rat DRG neurons, and it showed no toxic effect when intraperitoneally injected into mouse. We suggested that $\mu$-SPRTX-Hv2 is a promising candidate for developing novel bioinsecticide. Another toxin, $\omega$-SPRTX-Hv1a, isolated from the same spider venom, was reported to be a blocker of $\mathrm{Ca}_{\mathrm{V}} \mathrm{s}$ in cerebellar granule cells (Patent number US5627154, 6-May-1997). The $\mu$-SPRTX-Hv2 sequence is highly homologous to that of $\omega$-SPRTX-Hv1a, and their sequence variations mainly located in toxins' $\mathrm{N}$-terminus and C-terminus (six out of seven amino acid substitutions, Figure 1G). It is interesting to investigate their structural and pharmacological differences in future studies, including testing the activity of $\omega$-SPRTX-Hv1a on insect Navs and that of $\mu$-SPRTX-Hv2 on Cavs in cerebellar granule cells. As a previous study showed even a single amino acid mutation could change both the target selectivity and action mechanism of peptide toxins [26].

The first insect $\mathrm{Na}_{\mathrm{V}}$ gene (para) was cloned from Drosophila melanogaster [27]. After that, lots of studies had cloned $\mathrm{Na}_{\mathrm{V}}$ genes from many arthropod pests and disease vectors [28], and most insects have only one para-like $\mathrm{Na}_{\mathrm{V}}$ gene. $\mathrm{Na}_{\mathrm{V}}$ channels from different insect species have high level of identity (an alignment showed $87-97 \%$ identity between several insect species), thus many $\mathrm{Na}_{\mathrm{V}}$-targeting insecticides had a broad activity across many insects orders [29]. We speculated that $\mu$-SPRTX-Hv2 is also a broad-spectrum insecticide but it is yet to be experimentally determined. In Blattella germanica, the $\mathrm{Na}_{\mathrm{V}}$ gene is $\mathrm{BgNa}_{\mathrm{V}}$ [30]. However, alternative splicing and RNA editing of $\mathrm{BgNa}_{\mathrm{V}}$ gene could result in an array of $\mathrm{Na}_{\mathrm{V}} \mathrm{s}$ with different pharmacology and gating properties [31,32]. From this point of view, the Navs currents in the isolated DUM neurons might be mediated by several types of $\mathrm{BgNa}_{V}$ channels, but they all were blocked by $\mu$-SPRTX-Hv2. There are eight neurotoxin binding sites in Navs, namely site 1-7 and a local anesthetic (LA) binding site [10]. Among them, site 1 , site 3 , site 4 , and site 6 are receptor sites of peptide toxins, with toxins binding to site 3 and site 6 inhibiting the fast inactivation process, and toxin binding to site 1 and site 4 affecting channel activation. The toxin $\mu$-SPRTX-Hv2 in this study inhibited Navs currents without affecting the inactivation process. We speculated that: (1) $\mu$-SPRTX-Hv2 might be a site 1 toxin which functioned by physically blocking the ion conducting pathway, as those of guanidinium toxins (STX and TTX) and $\mu$-Conotoxins acting on mammalian Navs [10]; (2) or, $\mu$-SPRTX-Hv2 bound to the DII S3-4 linker and acted as a gating modifier toxin of insect $\mathrm{Na}_{V}$ s. Similarly to HWTX-IV acting on $\mathrm{Na}_{V} 1.7$ channel, $\mu$-SPRTX-Hv2 did not change the steady-state activation curve of insect $\mathrm{Na}_{V} s$ at physiological depolarizing voltages [33]. The blocking effect of $\mu$-SPRTX-Hv2 to insect Navs was irreversible, as that of $\delta$-hexatoxin-MrIX acting on mammalian Navs [34], suggesting a stable association of the toxin with its binding site. This irreversible binding property of $\mu$-SPRTX-Hv2 actually facilitated its use as an insecticide, and the molecular determinants in insect $\mathrm{Na}_{V}$ s for binding $\mu$-SPRTX-Hv2 are yet to be elucidated.

It is believed that spiders had an economical use of their venom in preying and defending $[35,36]$. Our previous study showed each $H$. venatoria spider yielded $2-15 \mu \mathrm{L}$ of venom and the venom density was $978 \mu \mathrm{g} / \mu \mathrm{L}$ [22], this translated to a very small volume of venom the spider needed to paralyze the cockroaches $\left(<0.1 \mu \mathrm{L}\right.$, the $\mathrm{LD}_{50}$ of the venom was $28.2 \mu \mathrm{g} / \mathrm{g}$ of body weight). Thus, it is obvious that $\mu$-SPRTX-Hv2 is not the only insecticidal component in H. venatoria venom, as it was only a small fraction of the venom and its $\mathrm{LD}_{50}$ to cockroaches was calculated to be $11.7 \mu \mathrm{g} / \mathrm{g}$ of body weight. The spider $H$. venatoria lives on insects, and its venom was optimized by evolution to paralyze or kill the insects. The next study could be to screen the H. venatoria venom for insecticidal components acting on other targets, such as $\mathrm{Ca}_{\mathrm{V}} \mathrm{s}$, calcium-activated potassium channels, and so on.

Although an orally active insecticidal peptide toxin, OAIP-1, was isolated from the venom of Australian tarantula Selenotypus plumipes [37], most of insecticidal peptide toxins were not active or with diminished activity when taken orally, which hampered their practical use. One strategy to overcome such a barrier was fusing GNA, a mannose-specific lectin from the snowdrop plant, to the 
insecticidal peptide toxin. As GNA facilitates the transport of the toxin through the insect gut and reaches its action site in the nervous system [38,39]. A previous study showed that the insecticidal fusion protein $\omega$-hexatoxin-Hv1a/GNA had no adverse effects on honeybees [40], which was a public concern of practical use of bioinsecticide in the natural environment. Another strategy was to use recombinant entomopathogen, which was genetically modified to express the insecticidal toxins and showed increased insecticidal potency $[41,42]$. This approach advanced in systemically producing the toxin in insect after pathogens infection and limiting the off-target effects by using the host selectivity of the pathogen. It is interesting to explore the practical use of $\mu$-SPRTX-Hv2 as bioinsecticide by using these approaches in future studies.

\section{Materials and Methods}

\subsection{Venom and Toxin Purification}

Spiders were captured in corners and eaves of old houses, maintained in terrariums in our laboratory, fed weekly with mealworms and water. A total of approximately 200 spiders were used for venom collection. The venom was collected by an electrical stimulation method as described in our previous study [43], lyophilized and preserved at $-80^{\circ} \mathrm{C}$. The crude venom was dissolved in $\mathrm{ddH}_{2} \mathrm{O}$ to a final concentration of $5 \mathrm{mg} / \mathrm{mL}$ and immediately subjected to the first round of semi-preparative RP-HPLC purification (C18 column, $10 \times 250 \mathrm{~mm}, 5 \mu \mathrm{m}$, Welch Materials Inc., Shanghai, China) using a $45-\mathrm{min}$ linear acetonitrile gradient from $5 \%$ to $55 \%$ at $3 \mathrm{~mL} / \mathrm{min}$ flow rate (Hanbon HPLC system equipped with NP7000 serials pump and NU3000 serials UV/VIS detector, Hanbon Sci.\&Tech., Huai'an, China). The fraction containing $\mu$-SPRTX-Hv2 was collected, lyophilized, and subjected to the second round of analytical RP-HPLC purification (C18 column, $4.6 \times 250 \mathrm{~mm}, 5 \mu \mathrm{m}$, Welch Materials Inc., Shanghai, China) using a 35-min linear acetonitrile gradient from $25 \%$ to $46 \%$ at $1 \mathrm{~mL} / \mathrm{min}$ flow rate (Shimadzu HPLC system equipped with LC-20AT pump and SPD-M20A detector, Shimadzu corporation, Kyoto, Japan). The purity of the toxin was tested by MALDI-TOF MS analysis (AB SCIEX TOF/TOF ${ }^{\mathrm{TM}} 5800$ system, Applied Biosystems, Foster City, CA, USA). All mass spectra were acquired in the positive reflectron mode, the laser intensity was 3800. The matrix for MALDI-TOF MS analysis was $\alpha$-Cyano-4-hydroxycinnamic acid.

\subsection{Toxin Sequence Determination}

The N-terminal sequence of $\mu$-SPRTX-Hv2 was determined by Edman degradation in an automatic protein sequencer (PerkinElmer Life Science Procise 491-A). The H. venatoria venom gland cDNA library database was created and submitted to NCBI by Chen. J et al. (College of Bioscience and Biotechnology, Hunan Agricultural University, Changsha, China). The full sequence of $\mu$-SPRTX-Hv2 was determined by blasting the $\mathrm{N}$-terminal sequence against the non-redundant protein sequences database by using the NCBI blast tool (https:/ / blast.ncbi.nlm.nih.gov / Blast.cgi).

\subsection{Solid-Phase Peptide Synthesis}

$\mu$-SPRTX-Hv2 was synthesized by using a Fmoc (N-(9-fluorenyl)methoxycarbonyl)/tert-butyl strategy and HOBt/TBTU/NMM coupling method [44]. The refolding buffer contains (in mM): $100 \mathrm{NaCl}, 5 \mathrm{GSH}, 0.5 \mathrm{GSSG}$, and 100 Tris (pH = 7.4, adjusted with $\mathrm{HCl}$ ). The linear peptide was diluted with the refolding buffer to a final concentration of $0.01 \mathrm{mg} / \mathrm{mL}$. The solution was stirred slowly at room temperature for $24 \mathrm{~h}$ and the refolding reaction was monitored by MALDI-TOF MS analysis. The reaction was terminated by adding TFA to a final concentration of $0.2 \%$, and the reaction mix was subjected to RP-HPLC purification (C18 column, $4.6 \times 250 \mathrm{~mm}, 5 \mu \mathrm{m}$, Welch Materials Inc., Shanghai, China) using a 35-min linear acetonitrile gradient from $25 \%$ to $46 \%$ at $1 \mathrm{~mL} / \mathrm{min}$ flow rate. The co-elution experiments were performed in Waters 2795 HPLC system equipped with Water 2487 detector (Waters Corporation, Milford, MA, USA) by using a 25-min linear acetonitrile gradient 
from $20 \%$ to $45 \%$ at $1 \mathrm{~mL} / \mathrm{min}$ flow rate (C18 column, $4.6 \times 250 \mathrm{~mm}, 5 \mu \mathrm{m}$, Welch Materials Inc., Shanghai, China).

\subsection{Bioactivity Assays}

Fifty-six cockroaches were randomly divided into eight groups ( $n=7$ in each group). Seven groups were used as experimental groups, to which $10 \mu \mathrm{L}$ toxin solution (dissolved in saline) was injected between the fourth and fifth sternite, at single dose of $0.29,0.53,0.96,1.74,3.09,5.56$, or $10 \mathrm{nmol} / \mathrm{g}$ for each group. The eighth group was used as experimental control and was injected with $10 \mu \mathrm{L}$ saline. Lethal effect was observed $24 \mathrm{~h}$ after injection. The $\mathrm{LD}_{50}$ value was determined by using the improved Karber's method [45]. For testing the toxicity of $\mu$-SPRTX-Hv2 to mouse, toxin at a single dose of $1.7 \mathrm{nmol} / \mathrm{g}(7.0 \mu \mathrm{g} / \mathrm{g}) \mathrm{was}$ injected intraperitoneally.

\subsection{Acute Dissociation and Culture of Rat DRG and Insect DUM Neurons}

SD rats and C57BL/ 6 mice (Hunan SJA Laboratory Animal Co., Ltd., Changsha, China) were used according to the guidelines of the National Institutes of Health for care and use of laboratory animals. The experiments were approved by the Animal Care and Use Committee of the College of Medicine, Hunan Normal University. DRG neurons were acutely dissociated from four-weeks-old SD rats and maintained in short-term primary culture as previously described [46]. Briefly, the dissociated dorsal root ganglia were transferred into Dulbecco's modified Eagle's medium (DMEM) containing trypsin $(0.5 \mathrm{mg} / \mathrm{mL}$, type III) and collagenase $(1.0 \mathrm{mg} / \mathrm{mL}$, type IA), then minced with scissor and digested at $37^{\circ} \mathrm{C}$ for $30 \mathrm{~min}$. Trypsin inhibitor $(1.5 \mathrm{mg} / \mathrm{mL}$, type II-S) was used to terminate the digestion process. The harvested neurons were seeded onto PLL-coated $3.5 \mathrm{~cm}$ dishes and cultured for additional $2-4 \mathrm{~h}$, allowing the cells to attach to the dish bottom.

DUM neurons were acutely dissociated from adult cockroaches as previously described [47]. Briefly, the abdominal ganglia were removed from beheaded cockroaches and digested in insect physiological solution (90 mM NaCl, $3.1 \mathrm{mM} \mathrm{KCl}, 2 \mathrm{mM} \mathrm{CaCl} 2,2 \mathrm{mM} \mathrm{MgCl} 2,140 \mathrm{mM}$ glucose, and $10 \mathrm{mM}$ HEPES $(\mathrm{pH}=6.8)$ ) containing papain $(20 \mathrm{U} / \mathrm{mL})$ at $37^{\circ} \mathrm{C}$ for $15 \mathrm{~min}$. The digestion was terminated with culture medium $\left(200 \mathrm{mM} \mathrm{NaCl}, 3 \mathrm{mM} \mathrm{KCl}, 5 \mathrm{mM} \mathrm{CaCl}, 4 \mathrm{mM} \mathrm{MgCl}_{2}, 50 \mathrm{mM}\right.$ sucrose and $10 \mathrm{mM}$ HEPES, 5\% fetal bovine serum, 1\% penicillin/streptomycin, $\mathrm{pH}=6.8)$. The harvested DUM neurons were seeded onto PLL-coated dishes and maintained in incubator $\left(5 \% \mathrm{CO}_{2}, 28{ }^{\circ} \mathrm{C}\right)$ for 2-3 $\mathrm{h}$ before performing patch-clamp analysis. Unless otherwise indicated, chemicals and reagents were products of Sigma-Aldrich (Sigma-Aldrich, St. Louis, MO, USA).

\subsection{Whole-Cell Currents Recording}

Whole-cell recordings of ion channel currents were performed in an EPC-10 patch-clamp platform (HEKA Elektronik, Lambrecht, Germany). The recording pipettes were prepared from glass capillaries (thickness $=0.225 \mathrm{~mm}$ ) with a PC-10 puller (NARISHIGE, Tokyo, Japan). The serial resistance was controlled to be $<10 \mathrm{M} \Omega$, and the voltage errors were compensated by using $80 \%$ serial resistance compensation, the speed value for serial resistance compensation was set to be $10 \mu \mathrm{s}$. The artificial capacitances were canceled by sequential fast and slow capacitance compensation by using the computer-controlled circuit of the amplifier. All experiments were performed at room temperature. For recording DRG Navs currents, the pipette solution contains (in mM):145 CsCl, $2 \mathrm{MgCl}_{2}, 10$ EGTA, 10 D-glucose, 2 ATP-Na $a_{2}$ and 10 HEPES ( $\mathrm{pH}$ 7.4), and the bath solution contains (in mM):145 NaCl, $2.5 \mathrm{KCl}, 1.5 \mathrm{CaCl}_{2}, 1.2 \mathrm{MgCl}_{2}, 10 \mathrm{D}$-glucose, and $10 \mathrm{HEPES}(\mathrm{pH}=7.4)$. For recording DRG Cavs currents, the pipette solution contains (in $\mathrm{mM}$ ): $120 \mathrm{CsCl}, 14$ phosphocreatine, 10 EGTA, 5 ATP-Mg and 10 HEPES ( $\mathrm{pH}$ 7.4), and the bath solution contains (in $\mathrm{mM}$ ): $2 \mathrm{BaCl}_{2}, 160$ tetraethylammonium (TEA)-Cl, $300 \mathrm{nM}$ TTX, 10 D-glucose and 10 HEPES, (pH = 7.4). For recording DUM Navs currents, the pipette solution contains (in mM): $140 \mathrm{CsF}, 2 \mathrm{MgCl}_{2}, 10$ EGTA and 10 HEPES ( $\mathrm{pH}=7.4$ ); and the bath solution contains (in $\mathrm{mM}$ ): $100 \mathrm{NaCl}, 30 \mathrm{TEA}-\mathrm{Cl}, 2 \mathrm{CaCl}_{2}, 4 \mathrm{KCl}, 10$ glucose, 50 choline-Cl, $1 \mathrm{CdCl}_{2}, 1$ 4-AP, and $10 \mathrm{HEPES}$ $(\mathrm{pH}=7.4)$. For recording DUM Ca $\mathrm{V}_{\mathrm{V}}$ currents, the pipette solution contains (in $\mathrm{mM}$ ): $10 \mathrm{Na}$-acetate, $110 \mathrm{CsCl}$, 
50 TEA-Br, 2 ATP-Na $2,0.5 \mathrm{CaCl}_{2}, 10$ EGTA, 10 HEPES (pH = 7.4); and the bath solution contains (in mM): $140 \mathrm{Na}$ acetate, $30 \mathrm{TEA}-\mathrm{Br}, 3 \mathrm{BaCl}_{2}, 300 \mathrm{nM}$ TTX, 10 HEPES ( $\mathrm{pH}=7.4$ ). For recording DUM KV currents, the pipette solution contains (in $\mathrm{mM}$ ): $135 \mathrm{~K}$-gluconate, $25 \mathrm{KF}, 9 \mathrm{NaCl}, 0.1 \mathrm{CaCl}_{2}, 1 \mathrm{MgCl}_{2}, 1 \mathrm{EGTA}$, 3 ATP-Na 2 , and 10 HEPES ( $\mathrm{pH}=7.4$ ); and the bath solution contains (in $\mathrm{mM}$ ): $200 \mathrm{NaCl}, 50 \mathrm{~K}$ gluconate, $5 \mathrm{CaCl}_{2} \cdot 2 \mathrm{H}_{2} \mathrm{O}, 4 \mathrm{MgCl}_{2} \cdot 6 \mathrm{H}_{2} \mathrm{O}, 300 \mathrm{nM}$ TTX, 10 D-glucose, and $10 \mathrm{HEPES}(\mathrm{pH}=7.4)$. For $\mathrm{Na}_{\mathrm{V}}$ subtype currents recording, $\mathrm{hNa} a_{\mathrm{V}} 1.3$ (with $97.18 \%$ identity to $\mathrm{rNa}_{\mathrm{V}} 1.3$ ), $\mathrm{rNa}_{\mathrm{V}} 1.4$, $\mathrm{hNa} \mathrm{V}_{\mathrm{V}} 1.5$ (with $94.01 \%$ identity to $\mathrm{rNa}_{\mathrm{V}} 1.5$ ), $\mathrm{hNa}_{\mathrm{V}} 1.7$ (with $92.05 \%$ identity to $\mathrm{rNa}_{\mathrm{V}} 1.7$ ), or $\mathrm{rNa}_{\mathrm{V}} 1.8$ cloned in pCDNA3.1 plasmid was co-transfected with pEGFP-N1 plasmid into HEK293T or ND7 / 23 cells, respectively, by using lipofectamine 2000 following the manufacturer's instructions. The pipette solution contains (in $\mathrm{mM}$ ): $140 \mathrm{CsCl}, 10 \mathrm{NaCl}$, 1 EGTA, 2 ATP-Mg, and 20 HEPES ( $\mathrm{pH}=7.4$ ); and the bath solution contains (in $\mathrm{mM}$ ): $140 \mathrm{NaCl}, 2 \mathrm{CaCl}_{2}$, $1 \mathrm{MgCl}_{2}, 5 \mathrm{KCl}, 20 \mathrm{HEPES}$, and 10 glucose $(\mathrm{pH}=7.4)$.

The electrophysiological data were acquired by using the Patch-Master software. Data were analyzed by using the software Sigma Plot 10.0, Origin 8, and Graphpad Prism 5.01 (GraphPad Software, La Jolla, CA, USA, 2007). The G-V and SSI curves were fitted by a Boltzmann equation: $\mathrm{y}=\mathrm{y}_{\text {steady }}+\left(\mathrm{y}_{(0)}-\mathrm{y}_{\text {steady }}\right) /\left(1+\exp \left[\left(\mathrm{V}-\mathrm{V}_{1 / 2}\right) / \mathrm{K}\right]\right)$, where $\mathrm{V}_{1 / 2}, \mathrm{~V}$ and $\mathrm{K}$ represented the midpoint voltage of kinetics, the test voltage, and the slope factor, respectively. The dose-response curves were fitted by a Hill equation to estimate the potency $\left(\mathrm{IC}_{50}\right)$ of the toxin. The toxin-channel association time constant ( $\tau_{\text {on }}$ value) in Figure $3 \mathrm{~A}$ was calculated by fitting the decay phase of the trace with the one phase decay equation: $\mathrm{y}=\left(\mathrm{y}_{(0)}-\mathrm{y}_{\text {steady }}\right) \times \exp (-\mathrm{k} \times \mathrm{x})+\mathrm{y}_{\text {steady }}$, in Graphpad Prism 5.01.

\subsection{Data Analysis}

Data were presented as MEAN $\pm \mathrm{SEM}, n$ was presented as the number of separate experimental cells.

Author Contributions: Z.L., C.T., and Z.X. conceived and designed the experiments; Z.X., Y.Z., and J.Z. performed the experiments; Z.L., C.T., Z.X., and S.L. analyzed the data; C.T., Z.L., and Z.X. wrote the paper.

Acknowledgments: This work was funded by National Nature Science Foundation projects of China (grant Nos. 31600669, 31570782, and 31370817).

Conflicts of Interest: The authors declare that they have no conflict of interest.

\section{References}

1. Vassilevski, A.A.; Kozlov, S.A.; Grishin, E.V. Molecular diversity of spider venom. Biochemistry (Mosc.) 2009, 74, 1505-1534. [CrossRef] [PubMed]

2. Escoubas, P.; Sollod, B.; King, G.F. Venom landscapes: Mining the complexity of spider venoms via a combined cdna and mass spectrometric approach. Toxicon 2006, 47, 650-663. [CrossRef] [PubMed]

3. Pineda, S.S.; Chaumeil, P.A.; Kunert, A.; Kaas, Q.; Thang, M.W.C.; Le, L.; Nuhn, M.; Herzig, V.; Saez, N.J.; Cristofori-Armstrong, B.; et al. Arachnoserver 3.0: An online resource for automated discovery, analysis and annotation of spider toxins. Bioinformatics 2018, 34, 1074-1076. [CrossRef] [PubMed]

4. Casida, J.E. Pest toxicology: The primary mechanisms of pesticide action. Chem. Res. Toxicol. 2009, 22, 609-619. [CrossRef] [PubMed]

5. Sattelle, D.B.; Cordova, D.; Cheek, T.R. Insect ryanodine receptors: Molecular targets for novel pest control chemicals. Invertebr. Neurosci. 2008, 8, 107-119. [CrossRef] [PubMed]

6. Figueiredo, S.G.; Garcia, M.E.; Valentim, A.C.; Cordeiro, M.N.; Diniz, C.R.; Richardson, M. Purification and amino acid sequence of the insecticidal neurotoxin $T \times 4(6-1)$ from the venom of the 'armed' spider Phoneutria nigriventer (keys). Toxicon 1995, 33, 83-93. [CrossRef]

7. Corzo, G.; Gilles, N.; Satake, H.; Villegas, E.; Dai, L.; Nakajima, T.; Haupt, J. Distinct primary structures of the major peptide toxins from the venom of the spider macrothele gigas that bind to sites 3 and 4 in the sodium channel. FEBS Lett. 2003, 547, 43-50. [CrossRef]

8. Corzo, G.; Escoubas, P.; Stankiewicz, M.; Pelhate, M.; Kristensen, C.P.; Nakajima, T. Isolation, synthesis and pharmacological characterization of delta-palutoxins IT, novel insecticidal toxins from the spider Paracoelotes luctuosus (Amaurobiidae). Eur. J. Biochem. 2000, 267, 5783-5795. [CrossRef] [PubMed] 
9. Bende, N.S.; Dziemborowicz, S.; Herzig, V.; Ramanujam, V.; Brown, G.W.; Bosmans, F.; Nicholson, G.M.; King, G.F.; Mobli, M. The insecticidal spider toxin sfi1 is a knottin peptide that blocks the pore of insect voltage-gated sodium channels via a large beta-hairpin loop. FEBS J. 2015, 282, 904-920. [CrossRef] [PubMed]

10. Stevens, M.; Peigneur, S.; Tytgat, J. Neurotoxins and their binding areas on voltage-gated sodium channels. Front. Pharmacol. 2011, 2, 71. [CrossRef] [PubMed]

11. Yang, S.; Fitches, E.; Pyati, P.; Gatehouse, J.A. Effect of insecticidal fusion proteins containing spider toxins targeting sodium and calcium ion channels on pyrethroid-resistant strains of peach-potato aphid (Myzus persicae). Pest Manag. Sci. 2015, 71, 951-956. [CrossRef] [PubMed]

12. Bende, N.S.; Dziemborowicz, S.; Mobli, M.; Herzig, V.; Gilchrist, J.; Wagner, J.; Nicholson, G.M.; King, G.F.; Bosmans, F. A distinct sodium channel voltage-sensor locus determines insect selectivity of the spider toxin dc1a. Nat. Commun. 2014, 5, 4350. [CrossRef] [PubMed]

13. Herzig, V.; Ikonomopoulou, M.; Smith, J.J.; Dziemborowicz, S.; Gilchrist, J.; Kuhn-Nentwig, L.; Rezende, F.O.; Moreira, L.A.; Nicholson, G.M.; Bosmans, F.; et al. Molecular basis of the remarkable species selectivity of an insecticidal sodium channel toxin from the african spider Augacephalus ezendami. Sci. Rep. 2016, 6, 29538. [CrossRef] [PubMed]

14. Wang, X.; Smith, R.; Fletcher, J.I.; Wilson, H.; Wood, C.J.; Howden, M.E.; King, G.F. Structure-function studies of omega-atracotoxin, a potent antagonist of insect voltage-gated calcium channels. Eur. J. Biochem. 1999, 264, 488-494. [CrossRef] [PubMed]

15. Wang, X.H.; Connor, M.; Wilson, D.; Wilson, H.I.; Nicholson, G.M.; Smith, R.; Shaw, D.; Mackay, J.P.; Alewood, P.F.; Christie, M.J.; et al. Discovery and structure of a potent and highly specific blocker of insect calcium channels. J. Biol. Chem. 2001, 276, 40306-40312. [CrossRef] [PubMed]

16. Deng, M.; Luo, X.; Meng, E.; Xiao, Y.; Liang, S. Inhibition of insect calcium channels by huwentoxin-v, a neurotoxin from Chinese tarantula Ornithoctonus huwena venom. Eur. J. Pharmacol. 2008, 582, 12-16. [CrossRef] [PubMed]

17. Dhadialla, T.S.; Gill, S.S. Insect midgut and insecticidal proteins. In Advances in Insect Physiology; Academic Press: Cambridge, MA, USA, 2014.

18. Jin, L.; Fang, M.; Chen, M.; Zhou, C.; Ombati, R.; Hakim, M.A.; Mo, G.; Lai, R.; Yan, X.; Wang, Y.; et al. An insecticidal toxin from nephila clavata spider venom. Amino Acids 2017, 49, 1237-1245. [CrossRef] [PubMed]

19. Smith, J.J.; Herzig, V.; Ikonomopoulou, M.P.; Dziemborowicz, S.; Bosmans, F.; Nicholson, G.M.; King, G.F. Insect-active toxins with promiscuous pharmacology from the African theraphosid spider Monocentropus balfouri. Toxins (Basel) 2017, 9, 155. [CrossRef] [PubMed]

20. Ikonomopoulou, M.P.; Smith, J.J.; Herzig, V.; Pineda, S.S.; Dziemborowicz, S.; Er, S.Y.; Durek, T.; Gilchrist, J.; Alewood, P.F.; Nicholson, G.M.; et al. Isolation of two insecticidal toxins from venom of the Australian theraphosid spider Coremiocnemis tropix. Toxicon 2016, 123, 62-70. [CrossRef] [PubMed]

21. Zhong, Y.; Song, B.; Mo, G.; Yuan, M.; Li, H.; Wang, P.; Yuan, M.; Lu, Q. A novel neurotoxin from venom of the spider, Brachypelma albopilosum. PLoS ONE 2014, 9, e110221. [CrossRef] [PubMed]

22. Huang, Y.; Wu, X.; Peng, Z.; Duan, Z.; Xi, Z.; Chen, M.; Farooq, A.; Liang, S.; Liu, Z. Peptide-rich venom from the spider Heteropoda venatoria potently inhibits insect voltage-gated sodium channels. Toxicon 2016, 125, 44-49. [CrossRef] [PubMed]

23. Sanguinetti, M.C.; Johnson, J.H.; Hammerland, L.G.; Kelbaugh, P.R.; Volkmann, R.A.; Saccomano, N.A.; Mueller, A.L. Heteropodatoxins: Peptides isolated from spider venom that block kv4.2 potassium channels. Mol. Pharmacol. 1997, 51, 491-498. [PubMed]

24. King, G.F.; Gentz, M.C.; Escoubas, P.; Nicholson, G.M. A rational nomenclature for naming peptide toxins from spiders and other venomous animals. Toxicon 2008, 52, 264-276. [CrossRef] [PubMed]

25. Kumar, S.; Stecher, G.; Tamura, K. MEGA7: Molecular evolutionary genetics analysis version 7.0 for bigger datasets. Mol. Biol. Evol. 2016, 33, 1870-1874. [CrossRef] [PubMed]

26. Peigneur, S.; Beress, L.; Moller, C.; Mari, F.; Forssmann, W.G.; Tytgat, J. A natural point mutation changes both target selectivity and mechanism of action of sea anemone toxins. FASEB J. 2012, 26, 5141-5151. [CrossRef] [PubMed]

27. Loughney, K.; Kreber, R.; Ganetzky, B. Molecular analysis of the para locus, a sodium channel gene in drosophila. Cell 1989, 58, 1143-1154. [CrossRef] 
28. Dong, K.; Du, Y.; Rinkevich, F.; Nomura, Y.; Xu, P.; Wang, L.; Silver, K.; Zhorov, B.S. Molecular biology of insect sodium channels and pyrethroid resistance. Insect Biochem. Mol. Biol. 2014, 50, 1-17. [CrossRef] [PubMed]

29. King, G.F.; Escoubas, P.; Nicholson, G.M. Peptide toxins that selectively target insect $\mathrm{Na}_{\mathrm{V}}$ and Cav channels. Channels 2008, 2, 100-116. [CrossRef] [PubMed]

30. Dong, K. A single amino acid change in the para sodium channel protein is associated with knockdown-resistance $(k d r)$ to pyrethroid insecticides in German cockroach. Insect Biochem. Mol. Biol. 1997, 27, 93-100. [CrossRef]

31. Tan, J.; Liu, Z.; Nomura, Y.; Goldin, A.L.; Dong, K. Alternative splicing of an insect sodium channel gene generates pharmacologically distinct sodium channels. J. Neurosci. 2002, 22, 5300-5309. [CrossRef] [PubMed]

32. Song, W.; Liu, Z.; Tan, J.; Nomura, Y.; Dong, K. RNA editing generates tissue-specific sodium channels with distinct gating properties. J. Biol. Chem. 2004, 279, 32554-32561. [CrossRef] [PubMed]

33. Xiao, Y.; Bingham, J.P.; Zhu, W.; Moczydlowski, E.; Liang, S.; Cummins, T.R. Tarantula huwentoxin-IV inhibits neuronal sodium channels by binding to receptor site 4 and trapping the domain II voltage sensor in the closed configuration. J. Biol. Chem. 2008, 283, 27300-27313. [CrossRef] [PubMed]

34. Tang, D.; Xiao, Z.; Xu, Y.; Zeng, J.; Peng, D.; Liang, S.; Tang, C.; Liu, Z. The peptide toxin delta-hexatoxin-MrIX inhibits fast inactivation of $\mathrm{Na}_{\mathrm{V}} \mathrm{s}$ in mouse cerebellar granule cells. Peptides 2018, 102, 47-53. [CrossRef] [PubMed]

35. Wigger, E.; Kuhn-Nentwig, L.; Nentwig, W. The venom optimisation hypothesis: A spider injects large venom quantities only into difficult prey types. Toxicon 2002, 40, 749-752. [CrossRef]

36. Cooper, A.M.; Nelsen, D.R.; Hayes, W.K. The strategic use of venom by spiders. Evol. Venom. Anim. Their Toxins 2015, 1-18.

37. Hardy, M.C.; Daly, N.L.; Mobli, M.; Morales, R.A.V.; King, G.F. Isolation of an orally active insecticidal toxin from the venom of an Australian tarantula. PLoS ONE 2013, 8, e73136. [CrossRef] [PubMed]

38. Fitches, E.; Audsley, N.; Gatehouse, J.A.; Edwards, J.P. Fusion proteins containing neuropeptides as novel insect contol agents: Snowdrop lectin delivers fused allatostatin to insect haemolymph following oral ingestion. Insect Biochem. Mol. Biol. 2002, 32, 1653-1661. [CrossRef]

39. Fitches, E.; Woodhouse, S.D.; Edwards, J.P.; Gatehouse, J.A. In vitro and in vivo binding of snowdrop (Galanthus nivalis agglutinin; GNA) and jackbean (Canavalia ensiformis; Con A) lectins within tomato moth (Lacanobia oleracea) larvae; mechanisms of insecticidal action. J. Insect Physiol. 2001, 47, 777-787. [CrossRef]

40. Nakasu, E.Y.; Williamson, S.M.; Edwards, M.G.; Fitches, E.C.; Gatehouse, J.A.; Wright, G.A.; Gatehouse, A.M. Novel biopesticide based on a spider venom peptide shows no adverse effects on honeybees. Proc. Biol. Sci. 2014, 281, 20140619. [CrossRef] [PubMed]

41. Wang, C.; Leger, R.J.S. A scorpion neurotoxin increases the potency of a fungal insecticide. Nat. Biotechnol. 2007, 25, 1455. [CrossRef] [PubMed]

42. Lovett, B.; St Leger, R.J. Genetically engineering better fungal biopesticides. Pest Manag. Sci. 2018, 74, 781-789. [CrossRef] [PubMed]

43. Hu, Z.; Zhou, X.; Chen, J.; Tang, C.; Xiao, Z.; Ying, D.; Liu, Z.; Liang, S. The venom of the spider selenocosmia jiafu contains various neurotoxins acting on voltage-gated ion channels in rat dorsal root ganglion neurons. Toxins 2014, 6, 988-1001. [CrossRef] [PubMed]

44. Pi, J.; Quan, M.; Zeng, X. Solid-phase chemical synthesis and oxidative refolding of hainantoxin-III. Chin. J. Chromatogr. 2007, 25, 399-403. [CrossRef]

45. Liang, S.; Qin, Y.; Zhang, D.; Pan, X.; Chen, X.; Xie, J. Biological characterization of spider (Selenocosmia huwena) crude venom. Zool. Res. 1993, 14, 60-65.

46. Hu, H.Z.; Li, Z.W. Substance p potentiates ATP-activated currents in rat primary sensory neurons. Brain Res. 1996, 739, 163-168. [CrossRef]

47. Forsyth, P.; Sevcik, C.; Martinez, R.; Castillo, C.; D'Suze, G. Bactridine's effects on dum cricket neurons under voltage clamp conditions. J. Insect Physiol. 2012, 58, 1676-1685. [CrossRef] [PubMed]

(C) 2018 by the authors. Licensee MDPI, Basel, Switzerland. This article is an open access article distributed under the terms and conditions of the Creative Commons Attribution (CC BY) license (http:/ / creativecommons.org/licenses/by/4.0/). 